\title{
COVID-19 Pandemic and Im/migrants' Elevated Health Concerns in Canada: Vaccine Hesitancy, Anticipated Stigma, and Risk Perception of Accessing Care
}

\author{
Shen $\operatorname{Lin}^{1}(\mathrm{D}$ \\ Accepted: 26 January 2022 / Published online: 25 February 2022 \\ (c) The Author(s), under exclusive licence to Springer Science+Business Media, LLC, part of Springer Nature 2022
}

\begin{abstract}
Vaccine hesitancy has taken a toll on COVID-19 immunization globally. This study aims to characterize three COVID19-related health concerns (i.e., vaccine hesitancy, anticipated stigma, and risk perception) in Canada and how they differ based on im/migration status and other social determinants. Data were obtained from a nationwide probability sample of the Canadian Perspective Survey Series 3 (June 15 to 21, 2020). Multivariable binary logistic regression analysis was performed to investigate the association between each COVID-19 concern and nativity status, while controlling for socio-demographics. Of 3522 participants aged $\geq 25$ years, the estimated overall prevalence of vaccine hesitancy was $16.9 \%$, with im/migrants being greater than non-immigrants $(21.5 \%$ vs. $15.5 \%, \mathrm{p}<0.001)$. After controlling for all covariates, im/migrants had around two-fold greater odds of all three health concerns, including risk perception of accessing care (aOR 2.44, 95\% CI 1.89-3.15), anticipated stigma of being targeted (aOR 2.24, 95\% CI 1.81, 2.78) and COVID-19 vaccine hesitancy (aOR 1.99, 95\% CI 1.57-2.52), compared to their Canadian-born peers. Among vaccine-hesitant individuals $(n=596)$, im/migrants reported higher concerns, than non-immigrants, on vaccine safety $(71.3 \%$ vs. $49.5 \%)$, side effects $(66.4 \%$ vs $47.3 \%)$ and mistrust in vaccinations ( $12.5 \%$ vs $6.6 \%)$ as possible reasons of vaccine refusal. For migrant justice, health authorities should ensure equitable access to COVID-19 vaccines and other health-enhancing resources for im/migrants to mitigate their heightened fear, stigma, and mistrust of new vaccines amidst turbulent times.
\end{abstract}

Keywords COVID-19 immunization $\cdot$ Vaccine equity $\cdot$ COVID-19 stigma $\cdot$ Social determinants of health

\section{Background}

Although the novel coronavirus disease 2019 (COVID-19) can infect anyone, migrant and impoverished populations carry a disproportionate burden of the disease [1-3], which has heightened awareness of existing health gaps between the privileged social groups and those vulnerable populations. Similar to previous outbreaks of influenza and severe acute respiratory syndrome [4], what the COVID-19 pandemic brings to the forefront is that both exposures to health hazards and access to health-enhancing resources are fundamentally different based on nativity, class, race and many

Shen Lin

lamsonlin.lin@mail.utoronto.ca

Factor-Inwentash Faculty of Social Work, University of Toronto, 246 Bloor Street W, Toronto, ON M5S 1V4, Canada other social positions [5], also known as social determinants of health [6]. A burgeoning body of evidence has demonstrated overrepresentation of immigrants, low-income, and other socially marginalized populations among cases of and deaths from COVID-19 across the globe $[3,7]$. While COVID-19 vaccine distribution is the most cost-effective strategy for reducing mortality and achieving population immunity, the benefits of COVID-19 vaccines are not equitably shared by all sectors of society [8-10].

Immigrants, refugees, and migrant (im/migrant) populations include more than nine million foreign-born people living in Canada, representing hundreds of cultures and languages, and account for $80 \%$ of Canada's population increase [11]. Despite their contributions to social and economic progress, these diverse communities are at higher risk of exposure to COVID-19 pathogens [5], as statistics have shown that migrants were heavily represented in essential industries requiring extensive interaction with the public, living in overcrowded multi-generational housing, and 
frontline healthcare occupations including personal support worker and nurse aide [12]. These vulnerable conditions all speak to populations at risk prioritized for initial vaccine roll-out as defined by the National Advisory Committee on Immunization in Canada [13]. However, the challenge of low vaccine access is persistent for im/migrant and refugee populations, who often experience discrimination and suboptimal treatments when accessing local health services even under normal circumstances before the pandemic [14]. While "universality" is a cornerstone of the Canada Health Act, health care inequity still disproportionately affects im/migrant populations [15-17]. Compared to Canadian-born residents, $\mathrm{im} /$ migrants are more likely to lack a regular doctor [18], experience difficulties in accessing immediate care [19] and encounter barriers in obtaining selected diagnostic tests [20], all of which lead to greater unmet healthcare needs [21]. In addition, the inadequacy of culturally sensitive health care [22], the lack of interpretation services [15], limited health insurance eligibility [17] and the arbitrary 3-month wait period for insurance coverage [23] further exacerbate im/migrants' mistrust in the Canadian health care system. These pre-existing access problems, together with recently widespread misinformation around the pandemic [24] (i.e., the COVID-19 "infodemic"), could give rise to the vaccine hesitancy-one of the top 10 global health threats in 2019 as declared by the World Health Organization (WHO) [25]as well as stigma and fear accompanying COVID-19-" the greatest enemy" named by the United Nations [26].

It is worth noting that the framing of "vaccine hesitancy" in this study is not to shift responsibility on individuals, but rather as an indicator of public (mis)trust in health services that is rooted in a social, economic, political, and historical context [27], where systemic racism and neglect, as well as the legacy of unethical medical establishment that exploited marginalized communities are embedded in the Western society $[8,28]$. Following this line of inquiry, research has identified broader social and political determinants, including socioeconomic insecurity [29], experience of racial discrimination [30], exposure to vaccine misinformation [31, 32], system failures of vaccine accessibility [33], mistrust in the government and medical organizations [34], inappropriate crisis governance [35] as strong predictors of vaccine hesitancy in the general population. Meanwhile, the study acknowledges that the use of "vaccine hesitancy" may inadvertently stigmatizes marginalized populations if not articulated with cautions [36], while there are other more neutral terminologies such as vaccine acceptance, vaccine risk perception, vaccination intent and vaccine confidence that may not capture the full scope of such multi-faceted phenomenon-see further discussion [33]. Yet, in line with the critiques against the individualistic "victim-blaming" discourse $[8,37,38]$, this study, on the one hand, retains the term "vaccine hesitancy" to counteract its pervasive dialogue [33], and on the other hand, reinterprets this concept as the crisis of trust in vaccines and the authorities delivering them-a product stemming from maldistribution of power and healthenhancing resources across social groups that entails "selfscrutiny by our scientific and governmental bodies regarding their own credibility as well as investment" in resourcedeprived populations [37]. By taking a structural equity lens, this study situates COVID-19-related health concerns including vaccine hesitancy beyond personal choices and posits that healthcare 'choices' are delimited by supraindividual forces as well as broader structural constraints, especially for oppressed minority groups.

\section{Study Aims}

The arrival of COVID-19 in Canada presents an unprecedented public health challenge, with over 2.3 million confirmed cases, 30 thousand deaths to date [39], and the adjusted case fatality rate estimated to be $3.36 \%$ nationwide as of December 15, 2020 [40], which is substantially greater than seasonal influenza death rate of approximately $0.1 \%$ [41]. In fact, Canada is among top countries for a fast growth of COVID-19 vaccination coverage, with $83 \%$ of the eligible population (aged 12 and over) having received at least one dose and about $76 \%$ being fully vaccinated as of August 8 , 2021 [42]. However, with the success of COVID-19 vaccine rollout in Canada and around the world, there has been widespread concern regarding vaccine uptake, accessibility, and equity [43, 44]. While a growing body of research has documented disparities in COVID-19 vaccine hesitancy in relation to race/ethnicity $[45,46]$ and socioeconomic status [29], little has adopted an im/migrant equity lens to examine the pandemic fear, stigma, and vaccine hesitancy simultaneously. In addition, more contagious COVID-19 variants (e.g., the Delta variant, the Omicron variant) have jeopardized current vaccination achievements by putting unvaccinated or non-fully vaccinated adults at higher risk of hospitalization and intensive care use [47, 48], rendering the booster vaccine (supplemental doses) a heated debate for the pandemic control while balancing vaccine equity globally [49].

This study aims to characterize three major COVID19-related health concerns in Canada with a focus on identifying nativity disparities in vaccine hesitancy, anticipated stigma of being targeted, and perceived health risks of accessing care. Recognizing that im/migrant communities may be more susceptible to COVID-19 infection and underserved by host countries' health systems [25], the present study hypothesizes that migrants are more likely to have heightened COVID-19-related health concerns than their Canadian-born peers, despite a universal health-care system in Canada. Identifying the unique needs regarding vaccine 
beliefs, perceptions and practices of migrant populations and the sociodemographic subgroups that remain at-risk of COVID vaccine refusal are essential for informing appropriate evidence-based pandemic response across Canada. This study serves as a timely frame of reference for public health decision-makers to identify barriers to vaccination, optimise policy efforts to improve vaccine campaigns, allocate critical care interventions for recovery, and mitigate the pandemic's long-term societal harms. Therefore, the current study seeks to explore the relationship between three major health concerns and their determinants among Canadian adults by examining the following research questions:

(1) Do im/migrants have a higher prevalence and adjusted odds of COVID-19-related concerns, including vaccine hesitancy, anticipated stigma of being targeted, and risk perceptions of accessing care, than Canadian-born residents?

(2) Which demographic, economic, or social factors could potentially attenuate the association between COVID19 related health concerns and im/migration status?

(3) What other social determinants of health-representing socially vulnerable communities-are significantly associated with COVID-19-related concerns after accounting for im/migration status?

\section{Methods}

\section{Data Source, Research Context and Study Population}

The data was drawn from the third circle of the Canadian Perspective Survey Series-Resuming Economic and Social Activities During COVID-19 (CPSS3-COVID), an online nationwide survey, conducted from June 15 to 21 , 2020 [50]. The purpose of the cross-sectional CPSS survey series is to evaluate the health and socioeconomic consequences of the COVID-19 pandemic in Canada, starting from March 2020 [24]. The third survey, in particular, aims to examine whether Canadians will adhere to health and safety practices when the economy reopens and restrictions are loosened. The CPSS-3 was conducted three months after a provincial state of emergency declared in Ontario (Canada) on March 17, 2020, as a result of high COVID-19 transmission rates in the first wave of the COVID-19 outbreak. Beginning in late May 2020, the Public Health Agency of Canada (PHAC) has advised Canadians to wear a face mask in public areas. Since June 2020, various provinces in Canada, including Alberta, Ontario, and Québec, have entered Stage Two of the re-opening plan, allowing the re-opening of more business and an increase in social activities. On October 9, 2020, Health Canada approved the first COVID-19 vaccination, marking a significant step forward in Canada's fight against COVID-19 [51]. As such, the CPSS-3 data was collected four months before the first COVID-19 vaccine authorized for use in Canada.

The sampling frame of CPSS is a probabilistic panel (i.e., four rotation groups) from the Labour Force Survey (LFS) created by a stratified multi-stage sampling. Participants answering the LFS for the last time in April, May, June and July of 2019 was selected at random to participate in the CPSS and received emailed survey invitations with a link for online self-completion. Details of the survey methodology and data collection are available elsewhere [50]. The CPSS sampling frame represents $98 \%$ of the national populations and excludes persons living on First Nations reserves, the institutionalized population, and households in remote areas. The collection response rate of the CPSS- 3 was $58.1 \%$ and may reflect a tight schedule for data collection and COVID19-related fatigue during the pandemic. Those who did not report their health concerns about vaccine uptake, anticipated stigma of being targeted, perceived health risks (e.g., don't know, refusal, missing) and those aged less than 25 years were excluded from this study $(n=687)$, yielding a final sample size of 3522 . The age group of 15 to 24 was excluded from the study sample because many of them did not finish their schooling and lack financial independence.

\section{Ethical Considerations and Data Accessibility}

The analyses were solely based on the public-use microdata files (PUMF) available to both Canadian and international researchers via Statistics Canada's Data Liberation Initiative. The public-use data are completely de-identified and publicly available with necessary suppression methods to protect confidentiality; thus, according to the Tri-Council Policy Statement: Ethical Conduct for Research Involving Humans-TCPS 2 (2018), this study based on Statistics Canada PUMF was considered non-human subject research and did not require institutional ethics review.

\section{Dependent Variables}

COVID-19 vaccine hesitancy was measured by a single item asking respondents: When a COVID-19 vaccine becomes available, how likely is it that you will choose to get it?. The 4-point response was then reversely grouped into two levels to operationalize vaccine hesitancy $($ Hesitant $=$ somewhat unlikely and/or very unlikely to get the vaccine; Not hesi$\operatorname{tant}=$ somewhat likely and/or very likely to get the vaccine). Reasons for vaccine hesitancy Among those who indicated vaccine hesitancy, a follow-up question was asked: What are the reasons you would not get the COVID-19 vaccine? with a multiple-response set (9 options), such as Already had or 
think I have had COVID-19; Do not consider it necessary to get the vaccine; Not confident vaccine is safe; Do not believe in vaccination; Concern about risks and side effects; Have a pre-existing medical condition and Other reasons.

COVID-19 anticipated stigma was measured by a single item with a binary response (yes/no) asking respondents: Once your federal, provincial, territorial or municipal governments relax the measures put in place to fight COVID-19, do you fear being the target of unwanted behaviours because you may be judged for putting others at risk?. This variable operationalizes "concerns that one will experience future discrimination and bias" $[52,53]$ and reflects "anticipation of an adverse social judgment" in the future [54] that links labeled persons to negative stereotypes in the context of the COVID-19 pandemic [55, 56]. Reasons for anticipated stigma Among those who answered affirmatively, a followup question was asked: "For which reasons do you fear being the target?" with a multiple-response set (6 options), such as I do not wear a mask all the time; Job associated with risk of COVID-19; Health conditions cause me to cough or sneeze; I have other health conditions; I am elderly and Other reasons. Due to confidentiality restriction, the PUMF file collapsed two response categories by combining $M y$ racial identity and I live in a collective dwelling with other reasons. Similarly, two related options, I work in a hospital, other healthcare facility, seniors' residence, nursing home or other long-term care residence and My place of employment or my job, other than those listed above, is associated with risk of COVID-19, were merged as Job associated with risk of COVID-19.

Risk perception of accessing care was measured by a single item asking respondents: How concerned are you about the health risks of going to the doctor or hospital as the COVID-19 safety measures are relaxed?. The 3-point response was dichotomized: Yes $=$ very concerned/somewhat concerned; $\mathrm{No}=$ not at all concerned. Risk perception has been found as a predictor of preventive health behaviors as well as medical care avoidance during the COVID-19 outbreak $[57,58]$.

\section{Independent Variable}

\section{Im/migration Status}

The primary relationships of investigative interest were the differences between foreign-born im/migrants to Canada and Canadian-born residents in relation to three major health concerns during the COVID-19 pandemic. This is a derived variable provided by Statistics Canada based on two questions regarding country of birth (In what country were you born? and im/migration status (Are you now, or have you ever been, a landed immigrant in Canada?). Two categories of participants were compared: (1) im/migrants to Canada, including landed immigrants with permanent residence permission as well as foreign-born temporary residents with precarious migration status (i.e., temporary workers with work permit, international students with study permit, or are claiming refugee status); and (2) Canadian-born residents were treated as the reference group as it reflects a social location of privilege that shapes health care experience in a White settler society with history of colonization [17]. Unfortunately, this study based on the PUMF data was unable to tease out temporary residents as a separate category that was more vulnerable. Nevertheless, this variable of im/ migration status was regarded more than an individual attribute but as an embodied social position of power structures that "rank people into social hierarchies and (re)distribute social determinants of health" [59].

\section{Other Potential Confounders}

Demographics (age, sex), socioeconomic status (highest level of education, perceived income adequacy, employment status) and enabling factors (types of dwelling, marriage, municipality, living with spouse, household size) that could potentially attenuate the relationship between three major COVID-19-related health concerns and im/migration status were examined in the analysis. Perceived income adequacy during the pandemic was measured by asking respondents: Overall, since the beginning of the COVID-19 restrictions, is your household income enough to meet your household's needs for transportation, housing, food, clothing and other necessary expenses?. The response was coded as (1) more than enough; (2) enough; (3) not enough; (4) prefer not to say. Employment status was a variable to investigate the pandemic's impact on labour participation (defined as those who had worked at least one hour for pay, including self-employment) in the past 7 days prior to the survey (i.e., June 7 to June 13, 2020), with a specific focus to detect precarious employment/job precarity caused by the COVID19 pandemic [24]. Consistent with prior literature [24], the response was categorized into five groups: (1) employed and at work for at least part of the week; (2) employed but absent for the entire week due to COVID-19 (e.g., business closure, layoff, or personal circumstances including COVID19 diagnosis); (3) employed but absent for the entire week due to other reasons not related to COVID-19 (e.g., vacation, work schedule, seasonal business, maternity or parental leave, illness other than COVID-19); (4) not employed; (5) not stated. To measure the direct disruption from the COVID-19 pandemic, respondents who had a casual job with no work available at reference week were not considered as absent from work. In addition to aforementioned confounders, three COVID-19-related health concerns were also served as covariates for each other in the model. 


\section{Statistical Analysis}

First, descriptive analyses were conducted to describe the sample characteristics and three COVID-19-related concerns in the general Canadian population. Second, cross-tabulation analyses were generated by Chi-square tests $\left(\chi^{2}\right)$ using weighted percentages to compare group differences based on im/migration status and vaccine hesitancy, respectively. Third, adjusted odds ratios (aOR) and $95 \%$ confidence interval $(95 \% \mathrm{CI})$ were derived from binary logistic regression to examine associations between im/migration status and three major health concerns while adjusting for the covariates, with separate models predicting each health concern. Statistical analyses and data management were performed using the SPSS software package, Version 26 (IBM Corp., Armonk, N.Y., USA). A p-value $<0.05$ (two-tailed) was considered statistically significant. Model performance was assessed by the Nagelkerke $\mathrm{R}^{2}$ statistic (a measure of the proportion of explained variation in the logistic model). The weights provided by CPSS were normalized to produce population-representative estimates corrected for the altered sample size.

\section{Results}

\section{Sample Description and Bivariate Analysis}

As shown in Table 1, the overall sample $(\mathrm{n}=3522)$ mainly consisted of Canadians aged 25 years above, in a relationship (70.7\%), have enough perceived household income $(62.4 \%)$, graduated from college $(70.4 \%)$, living with a spouse $(72.6 \%)$, living in a single-detached house (61.5\%) and urban area (83.7\%). Information on the comparative distribution of these factors among Canadian-born residents $(\mathrm{n}=2924,83 \%)$ and migrants $(\mathrm{n}=598,17 \%)$ were provided. Chi-square statistics indicated that most demographic and socioeconomic factors significantly, other than sex and cohabitants, differed based on im/migration status $(\mathrm{p}<0.05)$. The population-weighted prevalence of vaccine hesitancy was $16.9 \%$ and thus vaccine acceptance rate was $83.1 \%$. Notably, migrants had significantly higher proportions of three major health concerns relative to Canadian-born residents: vaccine hesitancy $(21.5 \%$ vs. $15.5 \%)$, anticipated stigma of being targeted $(27.3 \%$ vs. $14 \%)$ and perceived health risks when accessing care (89\% vs. $76.3 \%$ ). Chi-square statistics also revealed that most covariates were associated with vaccine hesitancy $(\mathrm{p}<0.05)$, except for sex, marriage, and municipality.

Figures 1 and 2 further illustrate the possible reasons underlying two health concerns (i.e., anticipated stigma of being targeted and vaccine hesitancy) stratified by im/ migrant status respectively. Among individuals who reported anticipated stigma of being targeted as risky individuals (see Fig. $1, n=605$ ), there were disproportionately higher proportions of im/migrants attributing the anticipated stigma to other reasons (including racial identity) than their Canadian-born peers $(63.8 \%$ vs $21.7 \%$, $\mathrm{p}<0.001)$. Interestingly, Canadian-born residents had a higher percentage attributing the anticipated stigma to non-compliance with mask wearing than im/migrants $(57.9 \%$ vs $33.6 \%, \mathrm{p}<0.001)$, whereas reasons such as job-related risk of COVID-19 infection and stigma around the elderly did not differ significantly between these two groups. Among vaccine-hesitant individuals (see Fig. 2, $\mathrm{n}=596$ ), im/migrants had a significantly higher percentage reporting concerns on vaccine safety $(71.3 \%$ vs. $49.5 \%$, p < 0.001$)$, side effects $(66.4 \%$ vs $47.3 \%$, p < $0.001)$ and mistrust in vaccinations $(12.5 \%$ vs $6.6 \%, \mathrm{p}<$ $0.05)$ as reasons of vaccine refusal, compared to Canadianborn residents.

\section{Multivariable Logistic Regression}

Table 2 contains the multivariable-adjusted logistic regression analysis of the im/migration status and other confounders on three health concerns. Overall, as expected, $\mathrm{im} /$ migration status was positively associated with all three COVID-19-related health concerns (Research question 1). These positive correlations between im/migrants and health perceptions were very robust that could not be attenuated by a serious of significant confounders including age, sex, education, employment, perceived income, marriage, type of dwelling and other living conditions (Research question 2). In general, the Nagelkerke $R^{2}$ statistics indicate that the established model could explain $17 \%$ variance for vaccine hesitancy and close to $9 \%$ variance for the other two health concerns. Im/migrants had close to two-and-a-half greater odds of perceived health risks of accessing care when compared with Canadian-born residents (aOR 2.44, 95\% CI 1.89-3.15). Im/migrants also doubled the odds of reporting anticipated stigma of being targeted as risky individuals (aOR 2.24, 95\% CI 1.81, 2.78). Likewise, the odds of vaccine hesitancy were almost two times greater for im/migrants in Canada than their Canadian-born counterparts (aOR 1.99, 95\% CI 1.57-2.52).

Besides nativity-based disparities in health concerns, there were significant socio-demographic inequalities in the burden of COVID-19 health concerns (Research question 3). Female respondents had greater odds of reporting anticipated stigma of being targeted (aOR 1.23, 95\% CI 1.03-1.49) and vaccine hesitancy (aOR 1.26, 95\% CI 1.04-1.53) than their male peers. Social class also played a crucial role in shaping COVID-19 health concerns. For example, compared to those who had a bachelor's degree, respondents with lower educational attainments (i.e., high school graduate and/or 
Table 1 Population-weighted proportion of sample characteristics by im/migration status and vaccine hesitancy in the CPSS-3 (June 15-21, 2020), persons aged $\geq 25(\mathrm{~N}=3522)$

\begin{tabular}{|c|c|c|c|c|c|c|}
\hline & \multirow[t]{2}{*}{ Total sample } & \multicolumn{3}{|c|}{ By im/migration status (\%) } & \multicolumn{2}{|c|}{$\begin{array}{l}\text { By vaccine } \\
\text { hesitancy (\%) }\end{array}$} \\
\hline & & Can.-born & Im/migrants & $\chi^{2}$ & Hesitant & $\chi^{2}$ \\
\hline & $N=3522$ & $\mathrm{~N}=2924$ & $\mathrm{~N}=598$ & p-value & $\mathrm{N}=475$ & $\mathrm{p}$-value \\
\hline Vaccine hesitancy & & & & $<0.001$ & & - \\
\hline No & 83.1 & 84.5 & 78.5 & & - & \\
\hline Yes & 16.9 & 15.5 & 21.5 & & - & \\
\hline Anticipated stigma of being targeted & & & & $<0.001$ & & 0.616 \\
\hline No & 82.8 & 86.0 & 72.7 & & 17.1 & \\
\hline Yes & 17.2 & 14.0 & 27.3 & & 16.2 & \\
\hline Risk perceptions of accessing care & & & & $<0.001$ & & $<0.001$ \\
\hline No & 20.7 & 23.7 & 11.0 & & 25.3 & \\
\hline Yes & 79.3 & 76.3 & 89.0 & & 14.8 & \\
\hline $\begin{array}{l}\text { Covariates: demographic and socio- } \\
\text { economic factors }\end{array}$ & & & & & & \\
\hline Age & & & & $<0.001$ & & $<0.001$ \\
\hline 25 to 34 & 20.2 & 20.5 & 19.1 & & 21.8 & \\
\hline 35 to 44 & 18.3 & 17.1 & 22.0 & & 20.8 & \\
\hline 45 to 54 & 17.4 & 16.8 & 19.6 & & 21.7 & \\
\hline 55 to 64 & 19.1 & 21.3 & 11.8 & & 16.0 & \\
\hline$\geq 65$ & 25.1 & 24.3 & 27.5 & & 7.5 & \\
\hline Sex & & & & 0.48 & & 0.04 \\
\hline Male & 49.3 & 49.6 & 48.2 & & 15.6 & \\
\hline Female & 50.7 & 50.4 & 51.8 & & 18.2 & \\
\hline Education & & & & $<0.001$ & & $<0.001$ \\
\hline$\leq$ High school graduate & 29.6 & 30.0 & 27.9 & & 16.6 & \\
\hline College & 36.4 & 40.3 & 23.8 & & 21.7 & \\
\hline$\geq$ Bachelor's degree & 34.0 & 29.7 & 48.2 & & 12.1 & \\
\hline Perceived income adequacy & & & & $<0.001$ & & $<0.001$ \\
\hline More than enough & 17.7 & 19.5 & 11.7 & & 9.8 & \\
\hline Enough & 62.4 & 62.0 & 64.0 & & 16.8 & \\
\hline Not enough & 15.1 & 14.0 & 19.0 & & 25.6 & \\
\hline Prefer not to say & 3.6 & 3.3 & 4.6 & & 15.0 & \\
\hline Missing & NA & NA & NA & & NA & \\
\hline Employment status & & & & 0.047 & & $<0.001$ \\
\hline Employed \& at work & 50.1 & 50.6 & 48.4 & & 16.3 & \\
\hline Absent; COVID-19 related & 2.7 & 3.6 & 3.5 & & 8.5 & \\
\hline Absent; not COVID-19 related & 3.6 & 3.0 & 1.4 & & 21.3 & \\
\hline Not employed & 41.1 & 40.4 & 43.5 & & 16.8 & \\
\hline Not stated & 2.6 & 2.4 & 3.1 & & 33.3 & \\
\hline Type of dwelling & & & & $<0.001$ & & $<0.001$ \\
\hline Single detached house & 61.5 & 67.2 & 42.8 & & 15.7 & \\
\hline Low-rise apartment & 12.2 & 10.8 & 16.8 & & 18.1 & \\
\hline High-rise apartment & 9.6 & 6.9 & 18.1 & & 13.4 & \\
\hline Others & 16.7 & 15.0 & 22.3 & & 22.6 & \\
\hline Marriage & & & & $<0.001$ & & 0.386 \\
\hline Married/common-law & 70.7 & 69.1 & 76.0 & & 16.6 & \\
\hline Widowed/separated & 12.7 & 13.0 & 12.0 & & 16.3 & \\
\hline Single & 16.5 & 17.9 & 12.1 & & 18.9 & \\
\hline Municipality & & & & $<0.001$ & & 0.09 \\
\hline Rural & 16.3 & 20.1 & 4.0 & & 19.4 & \\
\hline
\end{tabular}


Table 1 (continued)

\begin{tabular}{|c|c|c|c|c|c|c|}
\hline & \multirow{3}{*}{$\begin{array}{l}\text { Total sample } \\
\mathrm{N}=3522\end{array}$} & \multicolumn{3}{|c|}{ By im/migration status (\%) } & \multicolumn{2}{|c|}{$\begin{array}{l}\text { By vaccine } \\
\text { hesitancy (\%) }\end{array}$} \\
\hline & & Can.-born & $\mathrm{Im} /$ migrants & $\chi^{2}$ & Hesitant & $\chi^{2}$ \\
\hline & & $\mathrm{N}=2924$ & $\mathrm{~N}=598$ & p-value & $N=475$ & $\mathrm{p}$-value \\
\hline Urban & 83.7 & 79.9 & 96.0 & & 16.5 & \\
\hline Living with spouse & & & & 0.078 & & 0.001 \\
\hline Yes & 72.6 & 71.9 & 75.0 & & 15.7 & \\
\hline No & 27.4 & 28.1 & 25.0 & & 20.2 & \\
\hline Household size & & & & $<0.001$ & & 0.009 \\
\hline 1 person & 16.6 & 17.8 & 12.8 & & 18.8 & \\
\hline 2 persons & 59.2 & 60.1 & 56.2 & & 15.3 & \\
\hline$\geq 3$ persons & 24.1 & 22.0 & 31.0 & & 19.5 & \\
\hline
\end{tabular}

$N A$ not available (due to small cell size $[\mathrm{n}<50]$, the estimates were not shown for quality control); Can.born Canadian-born residents

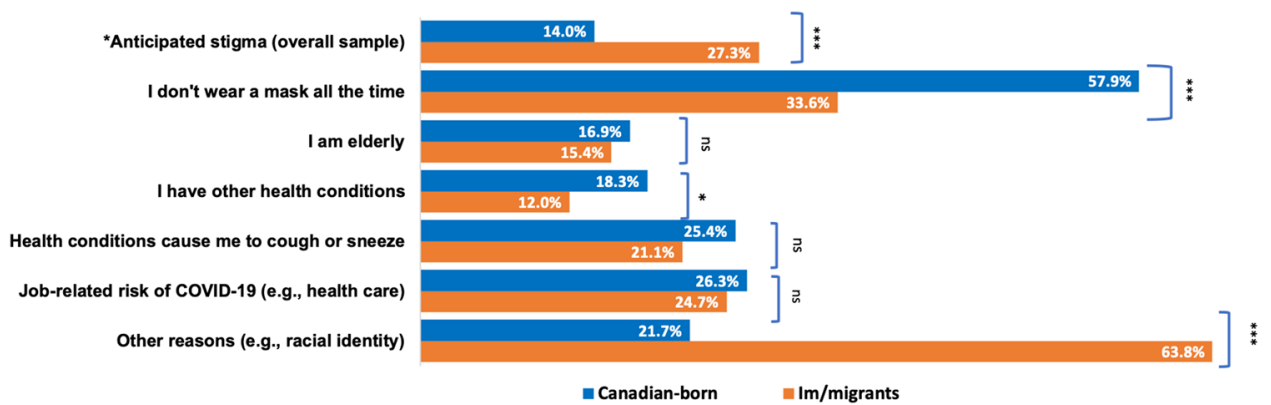

Fig. 1 Weighted prevalence of anticipated stigma (fear of being targeted) and its reasons by im/migration status in the CPSS-3 (June $15-21,2020)$, persons aged $\geq 25$. Notes $*$ Anticipated stigma was based on the overall sample $(n=3522$, Canadian-born $=2924$, $\mathrm{Im} /$ migrants $=598$ ), while other items (underlying reasons) were

below) had a higher likelihood of reporting perceived health risks of accessing care (aOR 1.36, 95\% CI 1.08-1.71) and vaccine hesitancy (aOR 1.67, 95\% CI 1.27-2.18). Similarly, when compared with affluent respondents (i.e., perceived income more than enough), impoverished individuals whose income cannot meet their financial needs during the COVID19 pandemic had a consistent pattern with greater odds of all three health concerns: perceived health risks when accessing health services (aOR 1.62, 95\% CI 1.19-2.22), anticipated stigma of being targeted (aOR 2.02, 95\% CI 1.46-2.80) and vaccine hesitancy (aOR $2.82,95 \%$ CI 1.96-4.06). The odds of vaccine hesitancy were also greater for those who were unemployed (aOR 1.55, 95\% CI 1.23-1.95), those who lived alone (aOR 1.85, 95\% CI 1.27-2.69) and live without a spouse (aOR 1.99, 95\% CI 1.35-2.95). On the contrary, the odds of vaccine hesitancy were lower for middle-aged adults (aOR $0.51,95 \%$ CI $0.37-0.70$ ), older persons (aOR $0.51,95 \%$ CI 0.37-0.70), those who were absent from work due to other reasons not related to the COVID-19 pandemic among individuals reported anticipated stigma $(n=605$, Canadianborn $=379, \quad \mathrm{Im} /$ migrants $=226$ ). Comparisons by $\mathrm{im} / \mathrm{migration}$ status were based on the chi-square test $(* \mathrm{p}<0.05 ; * * \mathrm{p}<0.01$; $* * * \mathrm{p}<0.001 ; n s$ not significant)

(aOR 0.40, 95\% CI 0.19-0.85), those who were widow/separated (aOR $0.39,95 \% \mathrm{CI} 0.24-0.63$ ), and those who were single/never married (aOR $0.37,95 \%$ CI 0.24-0.58). Interestingly, participants who reported risk perception of accessing health services reported lower odds of vaccine hesitancy (aOR $0.39,95 \%$ CI $0.31-0.48$ ), possibly due to their higher willingness to get immunisation protection against the risk of contracting COVID-19 virus.

\section{Discussion}

The current investigation examined the relationship between im/migration status and three COVID-19-related health concerns (i.e., perceived health risks when accessing care, anticipated stigma and vaccine hesitancy) among persons aged 25 years and older in Canada. The findings reveal that COVID-19-related health concerns are more prevalent among marginalized people who are migrants to Canada, those with lower educational attainment, and 


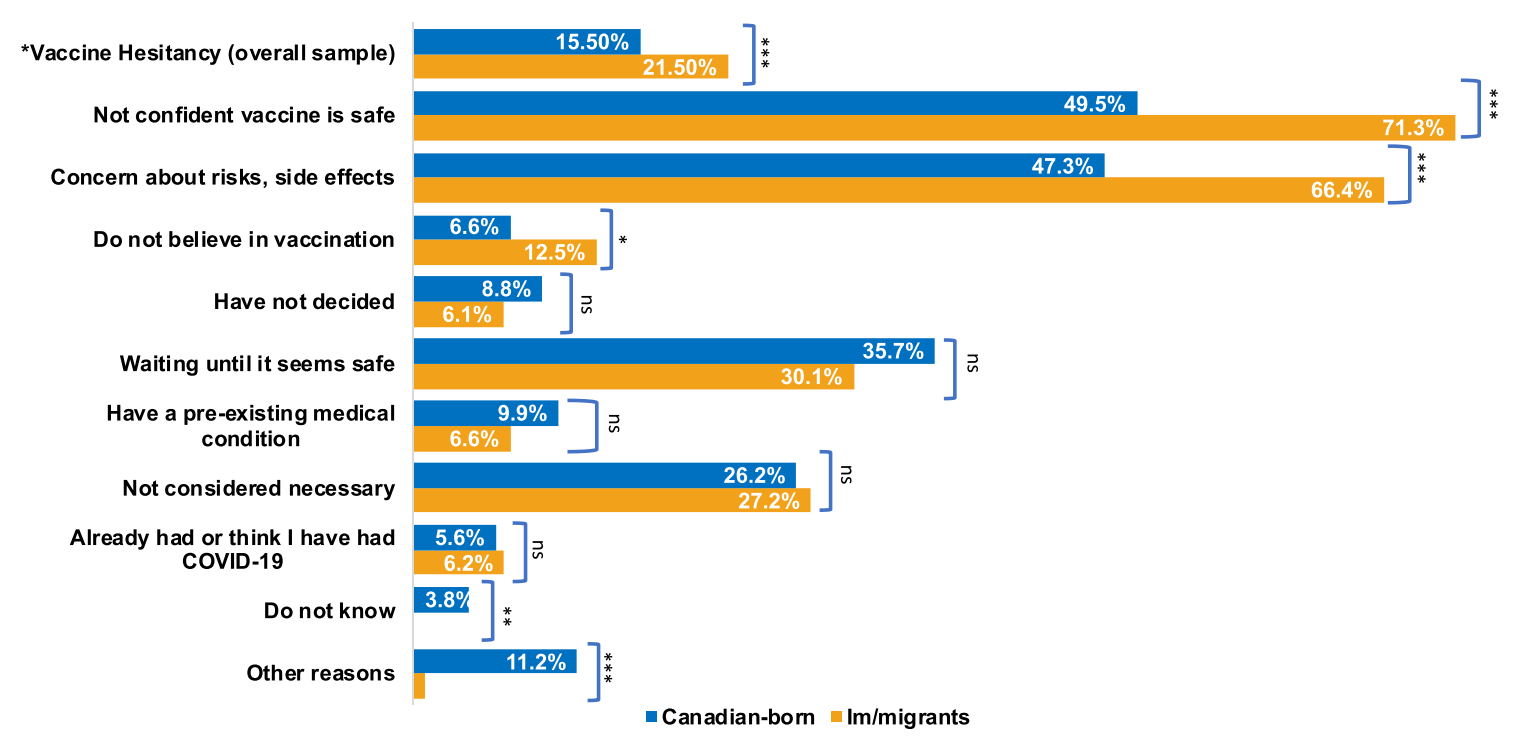

Fig. 2 Weighted prevalence of vaccine hesitancy and its reasons by im/migration status in the CPSS-3 (June 15-21, 2020), persons aged $\geq 25$. Notes *Vaccine hesitancy was based on the overall sample $(n=3522$, Canadian-born $=2924, \mathrm{Im} /$ migrants $=598)$, while other items (underlying reasons) were among vaccine-hesitant individuals $(\mathrm{n}=596$, Canadian-born $=379, \quad \mathrm{Im} /$ migrants $=226)$. Comparisons by im/migration status were based on the chi-square test $(* \mathrm{p}<0.05$; $* * \mathrm{p}<0.01 ; * * * \mathrm{p}<0.001 ; n s$ not significant)

infectious disease prevention, have been frequently documented among migrants $[15,25]$ racialized populations $[61$, 62] and socioeconomically disadvantaged groups [63], who are fundamentally deprived of health-promoting resources and at more risk of COVID-19 infection and adverse clinical outcomes [64]. In addition, this research demonstrates that health risk perceptions about seeing a doctor were more prominent in the $\mathrm{im} /$ migrant community, regardless of a publicly funded health care system in Canada. This is another worrying situation for im/migrants that could lead to underutilization of needed health services (e.g., delay of diagnostic tests and specialized care) in the host country during turbulence times [15, 65]. Thus, building COVID-19 vaccine confidence among these underserved populations primarily relies on the public health systems to become more accessible and sensitive on a structural basis, rather than placing the personal responsibility on these equity-seeking groups to become less hesitant [8]. For instance, decisionmakers could ensure equitable immunisation coverage by establishing pop-up COVID-19 vaccine clinics via community- and faith-based organizations where no appointments are required for free vaccines [66]. Local health authorities should listen to voices of im/migrant and refugee communities, such as the Migrant Rights Network, to prioritize resources to address their unmet needs for health and social care [17]. Proactive health communication-highlighting vaccine efficacy and safety via health care professionals to leverage pro-vaccine norms and counter-narrative to tackle misinformation-would also be effective in building public trust in new vaccines [67]. 
Table 2 Binary logistic regression analyses predicting the multivariable-adjusted odds ratios of (a) perceived health risks of accessing care, (b) anticipated stigma, and (c) vaccine hesitancy, respectively, in the CPSS-3 (June 15-21, 2020), persons aged $\geq 25(n=3522)$

\begin{tabular}{|c|c|c|c|c|c|c|c|c|c|c|c|c|}
\hline \multirow{4}{*}{$\begin{array}{l}\text { Explanatory variables } \\
\text { Im/migrants (Ref. Canadian-born) }\end{array}$} & \multicolumn{4}{|c|}{$\begin{array}{l}\text { Model A: Risk perceptions of } \\
\text { accessing care }\end{array}$} & \multicolumn{4}{|c|}{$\begin{array}{l}\text { Model B: Anticipated stigma } \\
\text { (Fear of being targeted) }\end{array}$} & \multicolumn{4}{|c|}{ Model C: Vaccine hesitancy } \\
\hline & $\mathrm{aOR}$ & $95 \%$ & & Sig & $\mathrm{aOR}$ & $95 \%$ & & Sig & $\mathrm{aOR}$ & $95 \%$ & & Sig \\
\hline & \multicolumn{4}{|c|}{ Nagelkerke $R^{2}=8.7 \%$} & \multicolumn{4}{|c|}{ Nagelkerke $\mathrm{R}^{2}=8.9 \%$} & \multicolumn{4}{|c|}{ Nagelkerke $\mathrm{R}^{2}=17.1 \%$} \\
\hline & 2.44 & 1.89 & 3.15 & $<0.001$ & 2.24 & 1.81 & 2.78 & $<0.001$ & 1.99 & 1.57 & 2.52 & $<0.001$ \\
\hline \multicolumn{13}{|l|}{ Age (Ref. 25-34) } \\
\hline 35 to 44 & 1.12 & 0.84 & 1.50 & 0.446 & 1.06 & 0.80 & 1.41 & 0.676 & 0.85 & 0.63 & 1.14 & 0.276 \\
\hline 45 to 54 & 0.91 & 0.68 & 1.22 & 0.518 & 1.22 & 0.91 & 1.63 & 0.187 & 0.89 & 0.66 & 1.20 & 0.447 \\
\hline 55 to 64 & 1.07 & 0.80 & 1.44 & 0.649 & 0.65 & 0.47 & 0.90 & 0.009 & 0.51 & 0.37 & 0.70 & $<0.001$ \\
\hline$\geq 65$ & 0.79 & 0.57 & 1.09 & 0.147 & 0.63 & 0.44 & 0.89 & 0.009 & 0.16 & 0.11 & 0.23 & $<0.001$ \\
\hline Female (Ref. Male) & 1.00 & 0.84 & 1.19 & 0.965 & 1.23 & $\mathbf{1 . 0 3}$ & 1.49 & 0.027 & 1.26 & 1.04 & 1.53 & 0.021 \\
\hline \multicolumn{13}{|l|}{ Education (Ref. $\geq$ BA degree) } \\
\hline$\leq$ High school grad & 1.36 & 1.08 & 1.71 & 0.010 & 1.15 & 0.90 & 1.46 & 0.264 & 1.67 & 1.27 & 2.18 & $<0.001$ \\
\hline College diploma & 1.33 & 1.08 & 1.64 & 0.009 & 0.97 & 0.77 & 1.22 & 0.807 & 2.17 & 1.70 & 2.77 & $<0.001$ \\
\hline \multicolumn{13}{|l|}{ Perceived income (Ref. $>$ Enough) } \\
\hline Enough & 1.46 & 1.17 & 1.83 & 0.001 & 1.23 & 0.95 & 1.61 & 0.120 & 1.70 & 1.25 & 2.32 & 0.001 \\
\hline Not enough & 1.62 & 1.19 & 2.22 & 0.002 & 2.02 & 1.46 & 2.80 & $<0.001$ & 2.82 & 1.96 & 4.06 & $<0.001$ \\
\hline Prefer not to say & 0.83 & 0.52 & 1.33 & 0.439 & 0.94 & 0.51 & 1.72 & 0.838 & 1.06 & 0.57 & 1.96 & 0.860 \\
\hline Missing & NA & NA & NA & 0.223 & NA & NA & NA & 0.896 & NA & NA & NA & 0.001 \\
\hline \multicolumn{13}{|l|}{ Employment (Ref. Employed) } \\
\hline Absent; COVID-19 related & 1.41 & 0.84 & 2.35 & 0.194 & 0.90 & 0.57 & 1.44 & 0.669 & 1.37 & 0.86 & 2.19 & 0.190 \\
\hline Absent; not COVID-19 related & 1.23 & 0.71 & 2.16 & 0.463 & 0.97 & 0.57 & 1.66 & 0.910 & 0.40 & 0.19 & 0.85 & 0.017 \\
\hline Not employed & 1.12 & 0.90 & 1.40 & 0.318 & 0.69 & 0.55 & 0.88 & 0.002 & 1.55 & 1.23 & 1.95 & $<0.001$ \\
\hline Not stated & 2.74 & 1.38 & 5.45 & 0.004 & 0.29 & 0.11 & 0.72 & 0.008 & 5.43 & 3.19 & 9.22 & $<0.001$ \\
\hline \multicolumn{13}{|l|}{ Dwelling (Ref. House) } \\
\hline Low-rise apartment & 1.59 & 1.15 & 2.18 & 0.005 & 1.09 & 0.81 & 1.46 & 0.578 & 0.93 & 0.67 & 1.27 & 0.635 \\
\hline High-rise apartment & 1.40 & 0.99 & 1.99 & 0.060 & 0.72 & 0.51 & 1.03 & 0.071 & 0.69 & 0.47 & 1.02 & 0.066 \\
\hline Others & 1.08 & 0.85 & 1.38 & 0.526 & 1.05 & 0.81 & 1.35 & 0.716 & 1.34 & 1.04 & 1.73 & 0.025 \\
\hline \multicolumn{13}{|l|}{ Marriage (Ref. Married) } \\
\hline Widowed/Separated & 0.71 & 0.46 & 1.08 & 0.110 & 1.04 & 0.65 & 1.69 & 0.862 & 0.39 & 0.24 & 0.63 & $<0.001$ \\
\hline Single/never married & 0.82 & 0.55 & 1.24 & 0.350 & 1.32 & 0.86 & 2.03 & 0.197 & 0.37 & 0.24 & 0.58 & $<0.001$ \\
\hline Rural residency (Ref. Urban) & 0.70 & 0.56 & 0.87 & 0.002 & 0.73 & 0.54 & 0.98 & $\mathbf{0 . 0 3 7}$ & 1.12 & 0.86 & 1.47 & 0.388 \\
\hline \multicolumn{13}{|l|}{ Household size (Ref. 2 persons) } \\
\hline 1 person & 0.68 & 0.48 & 0.95 & $\mathbf{0 . 0 2 3}$ & 0.70 & 0.49 & 1.01 & 0.058 & 1.85 & 1.27 & 2.69 & 0.001 \\
\hline$\geq 3$ persons & 0.91 & 0.73 & 1.14 & 0.410 & 0.86 & 0.68 & 1.08 & 0.182 & 1.01 & 0.80 & 1.29 & 0.919 \\
\hline Living without spouse (Ref. No) & 1.37 & 0.96 & 1.97 & 0.087 & 0.97 & 0.66 & 1.42 & 0.855 & 1.99 & 1.35 & 2.95 & 0.001 \\
\hline $\begin{array}{l}\text { Risk perception of accessing care } \\
\text { (Ref. No) }\end{array}$ & - & - & - & - & 1.00 & 0.79 & 1.27 & 0.998 & 0.39 & 0.31 & 0.48 & $<0.001$ \\
\hline Anticipated stigma (Ref. No) & 1.01 & 0.80 & 1.28 & 0.942 & - & - & - & - & 0.78 & 0.60 & 1.01 & 0.056 \\
\hline Vaccine Hesitancy (Ref. No) & 0.40 & 0.32 & 0.50 & $<0.001$ & 0.77 & 0.60 & 1.00 & 0.046 & - & - & - & - \\
\hline
\end{tabular}

Notes Boldface indicates statistical significance $(\mathrm{p}<0.05)$. All predictors are adjusted for all other covariates in the model

$a O R$ adjusted odds ratios, 95\% CI95\% confidence intervals for the adjusted odds ratios, NA not available (due to small cell size [n $<50$ ], the estimates were not shown for quality control). Sig. Significance (p-value), Ref. reference group, BA Bachelor's degree and above

This study is particularly relevant to the current context of widespread xenophobia and anti-immigrant sentiment escalated by the COVID-19 pandemic [68-70]. Our finding is novel and extend previous literature by revealing that more than one-quarter of the im/migrants in Canada were fear of being targeted as risky "others" when the government relaxes public health measures against COVID-19. More importantly, one-third of such anticipated stigma among im/migrants was due to "other reasons (e.g., racial identity)", rather than non-compliance with public health 
measures (e.g., no face masking) or underlying medical conditions during the COVID-19 crisis. The proportion of "other reasons" were substantially higher among im/migrant compared to Canadian-born residents, while "racial identity" was merged with "other reasons" by Statistics Canada. As such, one may speculate that the over-representation in "other reasons" for anticipated stigma among im/migrants may be primarily attributable to the racialized status and resultant exposure to racial discrimination, both of which are closely intertwined with im/migrant communities [17, 71]. To a broader scale, there is an urgent need to grapple with root causes of the longstanding im/migration-based inequities by pursuing structural interventions on xenophobic migration policy, occupational injustice, structural racism, and white supremacy [72].

In addition, the excess fear may be partly ignited by the framing of "foreign virus" that mistakenly blames the pandemic on foreign "others" [56, 73]. Although the CFSS survey was unable to untangle certain fear sources, migrants' double burden of anticipated stigma is concerning because daily stress and self-stigma have been associated with diminished well-being and increased mental health problems [74, 75], which can exacerbate health and mental health disparities already present in the im/migrant and refugee populations $[76,77]$. To intervene more upstream determinants and social forces, COVID-19 pandemic responses need to simultaneously confront xenophobia, stigmatization, and vaccine hesitancy as well as to reduce socioecomic inequities [52], such as sufficient access to anti-stigma public health messaging, employment sick leave benefits, paid leave for COVID-19 vaccination and vaccine injury compensation program. These social welfare policies and interventions could enhance vulnerable individuals' capacity to cope with day-to-day life challenges during a public health emergency [78]. Through these equity-oriented empowerment initiatives, vulnerable populations could be informed to address their justified questions about vaccine safety and have adequate resources to act on trustworthy health information.

\section{Strengths and Limitations}

This is the first population-based study, to our knowledge, to compare health concerns, including COVID-19 vaccine hesitancy, among im/migrants and non-immigrants during the COVID-19 pandemic in Canada. However, several methodological flaws and biases limited the generalisability. First, when factoring in the nonparticipation, the cumulative response rate to the CPSS-3 survey was round 14\% [50], possibly due to its online survey methods that exclude offline populations and respondent fatigue from previous CPSS survey series during COVID-19. Thus, this CPSS-3 survey is subject to high non-response bias and there is an overrepresentation of Canadian-born residents and two-person households in the sample [50]. Given im/migrants were not proportionately surveyed, the observed gaps between im/ migrants and non-immigrants in COVID-19 health concerns may be underestimated at the national level. Second, this study relied on self-reported survey data and therefore is susceptible to recall bias. The statistical models will always have the risk of 'residual confounding', resulting from unobserved characteristics that are not included in the analyses. For example, due to PUMF data restriction, the study could not tease out certain non-permanent residents, foreign-born groups, such as those on a student or work visa or asylum seekers, who were more vulnerable than the landed immigrant populations.

Moreover, the CPSS survey did not capture the race/ ethnicity identifier or country of origin; and thus omitted a racial equity lens that could distinguish racialized $\mathrm{im} /$ migrants apart from White im/migrants whose cultural beliefs, exposure to societal stressor, and health care utilization patterns significantly differed. Therefore, future research could focus on examining the within-group heterogeneity by intra-group membership instead of aggregating $\mathrm{im} /$ migrants as a homogeneous category. Since CPSS only includes participants speaking English or French, im/ migrants facing language barriers with greater health concerns were less likely to be surveyed, which may have biased the sample. Lastly, the CPSS did not collect the information about more complex reasons, such as negative experiences and discrimination from previous healthcare encounters, vaccine availability by location and timing, which may help to explain disparities in health concerns. As the ongoing pandemic continues to evolve, future studies should adjust for important social determinants of health, including im/ migrant and socioeconomic status that stratify access to health-enhancing resources, to predict vaccination rate and vaccine uptake disparities.

\section{Conclusion}

Overall, this nationwide study has demonstrated disparities by nativity, income and education in the prevalence of COVID-19-related health concerns and reasons for vaccination refusal under universal health coverage in Canada. In major im/migrant-receiving countries around the world, it is vital for the COVID-19 vaccination plans to proactively include migrant and displaced populations-regardless of their legal status - to address their heightened fear, stigma and vaccine hesitancy amidst turbulent times. Accountability should be held upon the governance and medical institutions to ensure equitable access to COVID-19 vaccines and other health-enhancing resources for im/migrant populations. With new COVID-19 virus variants spreading 
(e.g., the Omicron variant and other variants of concern) and COVID-19 vaccine distributing globally, health equity should be placed at the center of all policy responses designed to mitigate the disproportionate impact of the pandemic on underserved communities.

Acknowledgements The author, Shen (Lamson) Lin, is grateful to the University of Toronto (UofT) Doctoral Fellowship in sponsoring his Ph.D. study and research at the Factor-Inwentash Faculty of Social Work (FIFSW) from 2017 to 2022. He appreciates the rigorous doctoral training and applied research skills that he received from the FIFSW and the Dalla Lana School of Public Health (DLSPH) at the UofT. $\mathrm{He}$ also thanks his past social work learning and research experience from the Chinese University of Hong Kong where he obtained his Master's degree in Social Policy. He is indebted to the two anonymous reviewers for their constructive suggestions on the earlier version of this research article. Statistics Canada would like to thank Canadians who took the time to answer questions for the CPSS survey during the COVID-19 pandemic.

Disclaimer The opinions expressed in this manuscript are the author's own and do not reflect the views of Statistics Canada.

Author Contributions This is a solo-authored paper. SL: Conceptualization (lead); Methodology (lead); Writing—original draft (lead); Formal analysis (lead); Writing-review and editing (lead).

Funding This work was supported by the University of Toronto Fellowship (Doctoral Student Funding Packages).

Data Availability The public use microdata file of the Canadian Perspectives Survey Series is available to Canadian researchers via Statistics Canada's Data Liberation Initiative and to international researchers by request at dli-idd@ statcan.gc.ca from Statistics Canada. More information could be found: https://hdl.handle.net/11272.1/AB2/HHC2HD. The public-use data are completely de-identified and publicly available with necessary suppression methods to protect confidentiality; thus, according to the Tri-Council Policy Statement: Ethical Conduct for Research Involving Humans-TCPS 2 (2018), this study relied solely on Statistics Canada's publicly available data could be deemed as non-human subjects research and does not require institutional ethics review. TCPS Article 2.2 allows exemption of research based exclusively on publicly available data from research ethics board review. This exemption is based on the presence of a legally designated custodian who protects privacy.

\section{Declarations}

Conflict of interest The author declared no potential conflict with respect to the research, authorship, and/or publication of this article.

\section{References}

1. Abrams EM, Szefler SJ. COVID-19 and the impact of social determinants of health. Lancet Respir Med. 2020;8(7):659-61.

2. Ahmed F, Ahmed N, Pissarides C, Stiglitz J. Why inequality could spread COVID-19. Lancet Public Health. 2020;5:e240.

3. Bambra C, Riordan R, Ford J, Matthews F. The COVID-19 pandemic and health inequalities. J Epidemiol Commun Health. 2020;74(11):964-8.
4. Quinn SC, Kumar S, Freimuth VS, Musa D, Casteneda-Angarita N, Kidwell K. Racial disparities in exposure, susceptibility, and access to health care in the US H1N1 influenza pandemic. Am J Public Health. 1971;2011(101):285-93.

5. Wright L, Steptoe A, Fancourt D. Are we all in this together? Longitudinal assessment of cumulative adversities by socioeconomic position in the first 3 weeks of lockdown in the UK. J Epidemiol Commun Health. 2020;74(9):683-8.

6. Marmot M. Social determinants of health inequalities. Lancet. 2005;365:1099-104.

7. Ross J, Diaz CM, Starrels JL. The disproportionate burden of COVID-19 for immigrants in the Bronx, New York. JAMA Internal Med. 2020;180:1043-4.

8. Khan MS, Ali SAM, Adelaine A, Karan A. Rethinking vaccine hesitancy among minority groups. Lancet. 2021;397:1863-5.

9. Hardeman A, Wong T, Denson JL, Postelnicu R, Rojas JC. Evaluation of health equity in COVID-19 vaccine distribution plans in the United States. JAMA Netw Open. 2021;4:e2115653.

10. Omer SB, Benjamin RM, Brewer NT, Buttenheim AM, Callaghan T, Caplan A, Carpiano RM, Clinton C, DiResta R, Elharake JA, Flowers LC, Galvani AP, Lakshmanan R, Maldonado YA, McFadden SM, Mello MM, Opel DJ, Reiss DR, Salmon DA, Schwartz JL, Sharfstein JM, Hotez PJ. Promoting COVID-19 vaccine acceptance: recommendations from the lancet commission on vaccine refusal, acceptance, and demand in the USA. Lancet. 2021;398:2186-92.

11. Immigration, Refugees and Citizenship Canada: 2020 Annual Report to Parliament on Immigration. 2020; 2021

12. Government of Canada, Public Services and Procurement Canada: The contribution of immigrants and population groups designated as visible minorities to nurse aide, orderly and patient service associate occupations / by Martin Turcotte and Katherine Savage.: CS45-28/1-2020-32E-PDF - Government of Canada Publications - Canada.ca. 2020; 2021

13. Canada, Public Health Agency of: COVID-19: Preliminary guidance on key populations for early immunization. 2020; 2021

14. Edge S, Newbold B. Discrimination and the health of immigrants and refugees: exploring Canada's evidence base and directions for future research in newcomer receiving countries. J Immigr Minor Health. 2013;15:141-8.

15. Lin S. Access to health care among racialised immigrants to Canada in later life: a theoretical and empirical synthesis. Ageing Soc. 2021. https://doi.org/10.1017/S0144686X20001841.

16. Martin D, Miller AP, Quesnel-Vallée A, Caron NR, Vissandjée B, Marchildon GP. Canada's universal health-care system: achieving its potential. Lancet. 2018;391:1718-35.

17. Tuyisenge G, Goldenberg SM. COVID-19, structural racism, and migrant health in Canada. Lancet (British edition). 2021;397:650-2.

18. Siddiqi AA, Wang S, Quinn K, Nguyen QC, Christy AD. Racial disparities in access to care under conditions of universal coverage. Am J Prev Med. 2016;50:220-5.

19. Sanmartin C, Ross N. Experiencing difficulties accessing first-contact health services in Canada: Canadians without regular doctors and recent immigrants have difficulties accessing first-contact healthcare services. Reports of difficulties in accessing care vary by age, sex and region. Healthc Policy. 2006;1:103-19.

20. Clarke J: Difficulty accessing health care services in Canada. Canadian Government News 2016

21. Chowdhury N, Naeem I, Ferdous M, Chowdhury M, Goopy S, Rumana N, Turin TC. Unmet healthcare needs among migrant populations in Canada: exploring the research landscape through a systematic integrative review. J Immigr Minor Health. 2021:23:353-72. 
22. Thomson MS, Chaze F, George U, Guruge S. Improving immigrant populations' access to mental health services in Canada: a review of barriers and recommendations. J Immigr Minority Health. 2015;17:1895-905.

23. Hamel-Smith Grassby M, Wiedmeyer M, Lavergne MR, Goldenberg SM. Qualitative evaluation of a mandatory health insurance "wait period" in a publicly funded health system: understanding health inequities for newcomer im/migrant women. BMJ Open. 2021;11:e047597.

24. Lin SL. Generalized anxiety disorder during COVID-19 in Canada: gender-specific association of COVID-19 misinformation exposure, precarious employment, and health behavior change. $\mathbf{J}$ Affect Disord. 2022;302:280-292. https://doi.org/10.1016/j.jad. 2022.01.100

25. Tankwanchi AS, Bowman B, Garrison M, Larson H, Wiysonge CS. Vaccine hesitancy in migrant communities: a rapid review of latest evidence. Curr Opin Immunol. 2021;71:62-8.

26. The United Nations: Coronavirus COVID-19 risk increased to 'very high' but containment still possible. 2020; 2021

27. Larson HJ, Cooper LZ, Eskola J, Katz SL, Ratzan S. Addressing the vaccine confidence gap. Lancet. 2011;378:526-35.

28. Adhikari B, Cheah PY. Vaccine hesitancy in the COVID-19 era. Lancet Infect Dis. 2021;21:1086.

29. Ogilvie GS, Gordon S, Smith LW, Albert A, Racey CS, Booth A, Gottschlich A, Goldfarb D, Murray MCM, Galea LAM, Kaida A, Brotto LA, Sadarangani M. Intention to receive a COVID-19 vaccine: results from a population-based survey in Canada. BMC Public Health. 2021;21:1-14.

30. Savoia E, Piltch-Loeb R, Goldberg B, Miller-Idriss C, Hughes B, Montrond A, Kayyem J, Testa MA. Predictors of COVID-19 vaccine hesitancy: socio-demographics, co-morbidity, and past experience of racial discrimination. Vaccines. 2021;9:767.

31. Wilson SL, Wiysonge C. Social media and vaccine hesitancy. BMJ Glob Health. 2020;5:e04206.

32. Loomba S, de Figueiredo A, Piatek SJ, de Graaf K, Larson HJ. Measuring the impact of COVID-19 vaccine misinformation on vaccination intent in the UK and USA. Nat Hum Behav. 2021;5:337-48.

33. MacDonald NE. Vaccine hesitancy: definition, scope and determinants. Vaccine. 2015;33:4161-4.

34. Mesch GS, Schwirian KP. Social and political determinants of vaccine hesitancy: lessons learned from the H1N1 pandemic of 2009-2010. Am J Infect Control. 2015;43:1161-5.

35. Yang R, Penders B, Horstman K. Addressing vaccine hesitancy in china: a scoping review of chinese scholarship. Vaccines. 2020;8:2.

36. Siegel M, Critchfield-Jain I, Boykin M, Owens A, Muratore R, Nunn T, Oh J. Racial/ethnic disparities in state-level COVID-19 vaccination rates and their association with structural racism. J Racial Ethn Health Disparities. 2021. https://doi.org/10.1007/ s40615-021-01173-7.

37. Goldenberg MJ. Public misunderstanding of science? Reframing the problem of vaccine hesitancy. Perspect Sci. 2016;24:552-81.

38. Corbie-Smith G. Vaccine hesitancy is a scapegoat for structural racism. JAMA Health Forum. 2021;2:e210434-e210434.

39. Canada, Public Health Agency of: Coronavirus disease (COVID-19): Outbreak update. 2020; 2020

40. Shim E. Regional variability in COVID-19 case fatality rate in Canada, February-December 2020. Int J Environ Res Public Health. 2021;18:1839.

41. Jordan RE, Adab P, Cheng KK. Covid-19: risk factors for severe disease and death. BMJ. 2020;368:m1198.

42. Canada, Public Health Agency of: Demographics: COVID-19 vaccination coverage in Canada - Canada.ca. 2021; 2021
43. Houston AR, Murthy S. Canada is no global health leader on COVID-19 vaccine equity. Lancet (British edition). 2021;397:1803.

44. Peretti-Watel P, Seror V, Cortaredona S, Launay O, Raude J, Verger P, Fressard L, Beck F, Legleye S, L'Haridon O, Léger D, Ward JK. A future vaccination campaign against COVID-19 at risk of vaccine hesitancy and politicisation. Lancet Infect Dis. 2020;20:769-70.

45. Murphy J, Vallières F, Bentall RP, Shevlin M, McBride O, Hartman TK, McKay R, Bennett K, Mason L, Gibson-Miller J, Levita L, Martinez AP, Stocks TVA, Karatzias T, Hyland P. Psychological characteristics associated with COVID-19 vaccine hesitancy and resistance in Ireland and the United Kingdom. Nat Commun. 2021;12:1-15.

46. Robertson E, Reeve KS, Niedzwiedz CL, Moore J, Blake M, Green M, Katikireddi SV, Benzeval MJ. Predictors of COVID19 vaccine hesitancy in the UK household longitudinal study. Brain Behav Immun. 2021;94:41-50.

47. Rosenberg ES, Holtgrave DR, Dorabawila V, Conroy M, Greene D, Lutterloh E, Backenson B, Hoefer D, Morne J, Bauer U, Zucker HA. New COVID-19 cases and hospitalizations among adults, by vaccination status-New York, May 3-July 25. MMWR Morb Mortal Wkly Rep. 2021;2021:1150-5.

48. Griffin JB, Haddix M, Danza P, Fisher R, Koo TH, Traub E, Gounder P, Jarashow C, Balter S. SARS-CoV-2 infections and hospitalizations among persons aged $\geq 16$ years, by vaccination status-Los Angeles County, California, May 1-July 25, 2021. MMWR Morb Mortal Wkly Rep. 2021;70:1170-6.

49. Follmann D. Comment. Stat Med. 2021;40:2526-7.

50. Canada S: Canadian Perspectives Survey Series 3 2020- Resuming economic and social activities during COVID-19: Public use microdata file. 2020; 2021

51. Canada H: Health Canada authorizes first COVID-19 vaccine. 2020; 2021

52. Carmen H. Logie, · Janet M. Turan: How Do We Balance Tensions Between COVID-19 Public Health Responses and Stigma Mitigation? Learning from HIV Research. AIDS Behav 2020:1-4

53. Kane JC, Elafros MA, Murray SM, Mitchell EMH, Augustinavicius JL, Causevic S, Baral SD. A scoping review of healthrelated stigma outcomes for high-burden diseases in low- and middle-income countries. BMC Med. 2019;17:17.

54. Weiss MG, Ramakrishna J. Stigma interventions and research for international health. Lancet. 2006;367:536-8.

55. Link BG, Phelan JC. Conceptualizing stigma. Ann Rev Sociol. 2001;27:363-85.

56. Logie $\mathrm{CH}$. Lessons learned from HIV can inform our approach to COVID-19 stigma. J Int AIDS Soc. 2020;23:e25504.

57. Lu P, Kong D, Shelley M. Risk perception, preventive behavior, and medical care avoidance among American older adults during the COVID-19 pandemic. J Aging Health. 2021;33:577-84.

58. Majid U, Wasim A, Bakshi S, Truong J. Knowledge, (mis-) conceptions, risk perception, and behavior change during pandemics: a scoping review of 149 studies. Public Underst Sci. 2020;29:777-99.

59. Gkiouleka A, Huijts T, Beckfield J, Bambra C. Understanding the micro and macro politics of health: Inequalities, intersectionality \& institutions-a research agenda. Soc Sci Med. 2018;200:92-8.

60. Griffith J, Marani H, Monkman H. COVID-19 vaccine hesitancy in Canada: content analysis of Tweets using the theoretical domains framework. J Med Internet Res. 2021;23:e26874.

61. Ojha RP, Stallings-Smith S, Flynn PM, Adderson EE, OffuttPowell TN, Gaur AH. The impact of vaccine concerns on racial/ ethnic disparities in influenza vaccine uptake among health care workers. Am J Public Health. 2015;105:e35-41.

62. Clark EH, Fredricks K, Woc-Colburn L, Bottazzi ME, Weatherhead J. Preparing for SARS-CoV-2 vaccines in US immigrant 
communities: strategies for allocation, distribution, and communication. Am J Public Health. 1971;2021(111):577-81.

63. de Figueiredo A, Simas C, Karafillakis E, Paterson P, Larson HJ. Mapping global trends in vaccine confidence and investigating barriers to vaccine uptake: a large-scale retrospective temporal modelling study. Lancet (British edition). 2020;396:898-908.

64. Al-Oraibi A, Martin CA, Hassan O, Wickramage K, Nellums LB, Pareek M. Migrant health is public health: a call for equitable access to COVID-19 vaccines. Lancet Public Health. 2021;6:e144.

65. Burgess DJ, Ding Y, Hargreaves M, van Ryn M, Phelan S. The association between perceived discrimination and underutilization of needed medical and mental health care in a multiethnic community sample. J Health Care Poor Underserved. 2008;19:894-911.

66. Barry V, Dasgupta S, Weller DL, Kriss JL, Cadwell BL, Rose C, Pingali C, Musial T, Sharpe JD, Flores SA, Greenlund KJ, Patel A, Stewart A, Qualters JR, Harris L, Barbour KE, Black CL. Patterns in COVID-19 vaccination coverage, by social vulnerability and Urbanicity-United States, December 14, 2020-May 1, 2021. MMWR Morb Mortal Wkly Rep. 2021;70:818-24.

67. Solís Arce JS, Warren SS, Meriggi NF, Scacco A, McMurry N, Voors M, Syunyaev G, Malik AA, Aboutajdine S, Adeojo O, Anigo D, Armand A, Asad S, Atyera M, Augsburg B, Awasthi M, Ayesiga GE, Bancalari A, Björkman Nyqvist M, Borisova E, Bosancianu CM, Cabra García MR, Cheema A, Collins E, Cuccaro F, Farooqi AZ, Fatima T, Fracchia M, Galindo Soria ML, Guariso A, Hasanain A, Jaramillo S, Kallon S, Kamwesigye A, Kharel A, Kreps S, Levine M, Littman R, Malik M, Manirabaruta G, Mfura JLH, Momoh F, Mucauque A, Mussa I, Nsabimana JA, Obara I, Otálora MJ, Ouéaogo BW, Pare TB, Platas MR, Polanco L, Qureshi JA, Raheem M, Ramakrishna V, Rená I, Shah T, Shaked SE, Shapiro JN, Svensson J, Tariq A, Tchibozo AM, Tiwana HA, Trivedi B, Vernot C, Vicente PC, Weissinger LB, Zafar B, Zhang B, Karlan D, Callen M, Teachout M, Humphreys M, Mobarak AM, Omer SB. COVID-19 vaccine acceptance and hesitancy in low- and middle-income countries. Nat Med. 2021;27:1385-94.

68. Suleman S, Garber KD, Rutkow L. Xenophobia as a determinant of health: an integrative review. J Public Health Policy. 2018;39:407-23.
69. Dhanani LY, Franz B. Why public health framing matters: an experimental study of the effects of COVID-19 framing on prejudice and xenophobia in the United States. Soc Sci Med (1982). 2021;269:113572.

70. Le TK, Cha L, Han H, Tseng W. Anti-Asian xenophobia and Asian American COVID-19 disparities. Am J Public Health. 2020;110:1371-3.

71. Viruell-Fuentes EA, Miranda PY, Abdulrahim S. More than culture: structural racism, intersectionality theory, and immigrant health. Soc Sci Med. 1982;2012(75):2099-106.

72. Machado S, Goldenberg S. Sharpening our public health lens: advancing im/migrant health equity during COVID-19 and beyond. Int J Equity Health. 2021;20:1-3.

73. Devakumar D, Shannon G, Bhopal SS, Abubakar I. Racism and discrimination in COVID-19 responses. Lancet. 2020;395:1194.

74. Maio FGD, Kemp E. The deterioration of health status among immigrants to Canada. Glob Public Health. 2010;5:462-78.

75. Siddiqi A, Shahidi FV, Ramraj C, Williams DR. Associations between race, discrimination and risk for chronic disease in a population-based sample from Canada. Soc Sci Med. 2017;194:135-41.

76. Chen JA, Zhang E, Liu CH. Potential impact of COVID-19-related racial discrimination on the health of Asian Americans. Am J Public Health. 1971;2020(110):1624-7.

77. Lin SL, Kobayashi K, Tong H, Davison KM, Arora SRA, FullerThomson E. Close relations matter: the association between depression and refugee status in the Canadian Longitudinal Study on Aging (CLSA). J Immigr Minor Health. 2020;22:946-56.

78. Phelan JC, Link BG, Tehranifar P. Social conditions as fundamental causes of health inequalities: theory, evidence, and policy implications. J Health Soc Behav. 2010;51(Suppl):28.

Publisher's Note Springer Nature remains neutral with regard to jurisdictional claims in published maps and institutional affiliations. 